\title{
Wheat Cultivars at Different Decades Vary Widely in Grain-filling Characteristics in Shaanxi Province, China
}

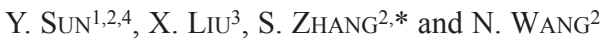 \\ ${ }^{1}$ Shaanxi Province Land Reclamation Engineering Technology Research Center, \\ Shaanxi Provincial Land Engineering Construction Group Co., Ltd., Xi'an 710075, China \\ ${ }^{2}$ State Key Laboratory of Soil Erosion and Dryland Farming on the Loess Plateau, \\ Northwest A\&F University, 26\# Xinong Road, Yangling 712100, China \\ ${ }^{3}$ Shanxi Normal University,1\# Gongyuan Street, Linfen 041000, China \\ ${ }^{4}$ Key Laboratory of Degraded and Unused Land Consolidation Engineering, \\ the Ministry of Land and Resources, Xi'an 710075, China \\ (Received 31 March 2017; Accepted 4 April 2018; \\ Communicated by R. N. Chibbar)
}

\begin{abstract}
Eight cultivars of dry-land wheat (Triticum aestivum L.) historically planted in Shaanxi Province, China, were grown in plots with irrigation and drought treatments during the growing seasons of 2011-2014, so as to characterize the differences in the rate and duration of the grain-filling stage among cultivars. The experimental results showed no obvious change among cultivars with respect to the duration of the grain-filling stage and no significant correlation between duration and grain weight. The filling rates of all three phases (lag, linear, and mature periods) showed significant differences among cultivars and had a greater effect on the grain weight than the duration of the filling stage, even though drought decreased the filling rate in the linear and mature periods. A lower filling rate led to a lighter grain weight in inferior grains than in superior grains. For the superior and inferior grains in the central spikelets, modern cultivars possess faster filling rates, especially in the lag and linear periods, whereas for the whole spike, no significant trend with cultivar replacement was observed. Faster filling rates with stable filling durations will be beneficial in obtaining additional yield increases.
\end{abstract}

Keywords: cultivar replacement, logistic equation, superior grains, yield potential

Abbreviations: FRa, filling rate, average; FD, filling duration; FR1, filling rate in 1st period (lag period); FD1, filling duration in 1st period (lag period); FR2, filling rate in 2nd period (linger period); FD2, filling duration in 2nd period (linear period); FR3, filling rate in 3rd period (mature period); FD3, filling duration in 3rd period (mature period).

\section{Introduction}

Grain filling in winter wheat determines the final grain weight, a key component of grain yield (Darroch and Baker 1990). To increase grain yield, cereal breeders have turned their attention towards grain filling as a possible measure of physiological efficiency. Both the 
duration and rate of grain growth in wheat can vary substantially depending on cultivar and environmental conditions (Sofield et al. 1977). In most cases, the duration of grain filling is more important than the rate of grain filling in contributing to a higher grain yield (Stoy 1965; Rawson and Evans 1971). However, Gebeyehou (1982), who worked with durum wheat, reported that grain yield was related to differences in the rate as well as duration of grain filling. Nass and Reiser (1975) confirmed that the filling rate was more productive than the duration of grain filling in grain weight.

A cereal crop panicle is composed of a large number of spikelets, and each spikelet is considered an individual unit in the complex inflorescence (Mohapatra and Sahu 1991; Murty and Murty 1982). The basal flowerets located on the middle spikelets of wheat spikes typically flower earlier, taking precedence in grain formation and filling, and obtain a higher grain weight (the so-called "superior grains"). In contrast, distal flowerets on the middle spikelets or those on the distal spikelets ("inferior grains") are smaller (Yang et al. 2014). Low grain weights are reported to be related to the late development of the endosperm, fewer endosperm cells, low grain-filling rates in the inferior grains (Ishimaru et al. 2003), and a shorter grain-filling duration (Zhang et al. 2010). The slow grain-filling rate and low grain weight of inferior spikelets have often been attributed to a limitation in carbohydrate supply (Yang et al. 2000). Despite their importance in superior and inferior grains of wheat, relatively little attention has been paid to these parameters (Chanda et al. 2002).

Drought is the most significant abiotic stress affecting plant growth and limiting crop yields (Finlay et al. 2007). Conditions at anthesis and the subsequent few days determine how many grains are set; high temperatures, low luminance and water stress at this stage are particularly unfavourable (Fischer and Maurer 1978). Stress caused by drought at the time of grain filling typically shortens the grain-filling period and reduces the grain-filling rate, leading to a reduction in grain yield (Aggarwal and Sinha 1984). Ultimate yield is determined not only by the rate of grain growth but also by its duration. How environments influence different cultivars varies, as some cultivars can maintain a high growth rate or long growth period under extreme weather conditions (Sofield et al. 1977).

In northern China, more than $70 \%$ of the precipitation falls during the monsoon months from June to September ( $\mathrm{Li}$ et al. 2000), and as a result, droughts are common during the growth stages of winter wheat. Hence, the key to increasing winter wheat productivity in this region lies in maximizing the utilization of precipitation with suitable wheat cultivars (Sun et al. 2014). In this study, to interpret the effects of cultivar replacement on grain filling characteristics in semi-humid areas, field research with different irrigation treatments was conducted in successive seasons to evaluate the logistic parameters of grain filling in different phases of cultivars used in different decades and how they influenced grain weight and yield. 


\section{Materials and Methods}

\section{Plant material and trial configurations}

Eight dry-land wheat cultivars formerly or currently planted in Shaanxi Province were selected (Table 1). Field experiments were conducted in Yangling, Shaanxi Province, in north-western China (3416’56.24’N , 108²'27.95'E; $460 \mathrm{~m}$ asl.) over the winter-spring growing season (October-June of the following year between 2011 and 2014).

Seeds of the experimental cultivars were planted in the field on October 10, 2011; October 12, 2012; and October 10, 2013. The soil is an Earth-cumuli-Orthic Anthrosol with a deep profile and is considered suitable for crop production. Mung beans were planted during the fallow period of each year, and irrigation was provided to regulate the soil moisture and fertilization. In the $2 \mathrm{~m}$ soil profile, the average field capacity was $28 \%$ $(\mathrm{q} / \mathrm{v})$.

Two irrigation treatments were implemented: one with normal rainfall and two irrigation events (irrigation, Ir) and another with no rainfall after the recovering stage (drought, D). Two irrigation events (70 $\mathrm{mm}$ each irrigation) were provided for the Ir treatment at the tillering stage and at the elongation stage to ensure the achievement of a high yield potential. Two exceptions occurred: during the elongation stage of 2011-2012, $80 \mathrm{~mm}$ of irrigation was provided at elongation due to dry weather, and in 2013-2014, $60 \mathrm{~mm}$ was provided at the tillering stage and no irrigation was provided at elongation due to wet weather. In addition, with adequate precipitation and irrigation from July to September 2013, precipitation was removed from the plots under drought treatment prior to the wintering stage.

The cultivars were planted manually in plots $(2.2 \times 3.3 \mathrm{~m}$ per plot; 11 rows, $20 \mathrm{~cm}$ apart; plant spacing of $2 \mathrm{~cm}$ ). The plots were arranged in randomized blocks with three replicates. Plots were arranged in randomized blocks with three replicates in 2011-2012 and 2012-2013; however, in 2013-2014, only two replicates were conducted. The precipitation during the growing seasons of all three years was recorded (Fig. 1).

Table 1. Representative cultivars of dry-land winter wheat introduced during the period 1940-2010 in Shaanxi Province

\begin{tabular}{|c|c|c|c|c|}
\hline Cultivar & $\begin{array}{c}\text { Planting } \\
\text { decade }\end{array}$ & Pedigree & Dwarf genes & Breeding sites \\
\hline Mazha & $1940 \mathrm{~s}$ & Local cultivar & None & Shaanxi Province \\
\hline Bima1 & $1950 \mathrm{~s}$ & Mazha/Biyu & None & Shaanxi Province \\
\hline Fengchan3 & $1960 \mathrm{~s}$ & Danmail/Xinong $6028 \times$ Bima1 & None & Shaanxi Province \\
\hline Taishan1 & $1970 \mathrm{~s}$ & 54405(Bima4×Zaoshu1)/Ourou & $R h t-D 1 b$ & Shandong Province \\
\hline Xiaoyan6 & $1980 \mathrm{~s}$ & $(\mathrm{ST} 2422 \times 464) /$ Xiaoyan96 & $R h t-B 1 b+R h t 8$ & Shaanxi Province \\
\hline Jinmai33 & $1990 \mathrm{~s}$ & $\begin{array}{l}\text { Pingyang79391((Naix } \\
\text { ue } \times 5017) 036 \times 76-1256) / \text { Pingyang76262 }\end{array}$ & None & Shanxi Province \\
\hline Changwu134 & $2000 \mathrm{~s}$ & $\begin{array}{l}\text { (Changwu131×Xiaohei96)F1/ } \\
\text { Changwu131)F4/(Jinghua3/NS2761)F1 }\end{array}$ & $R h t-B 1 b$ & Shaanxi Province \\
\hline Changhan58 & $2010 \mathrm{~s}$ & Changwu112/PH82-2 & $R h t-B 1 b$ & Shaanxi Province \\
\hline
\end{tabular}




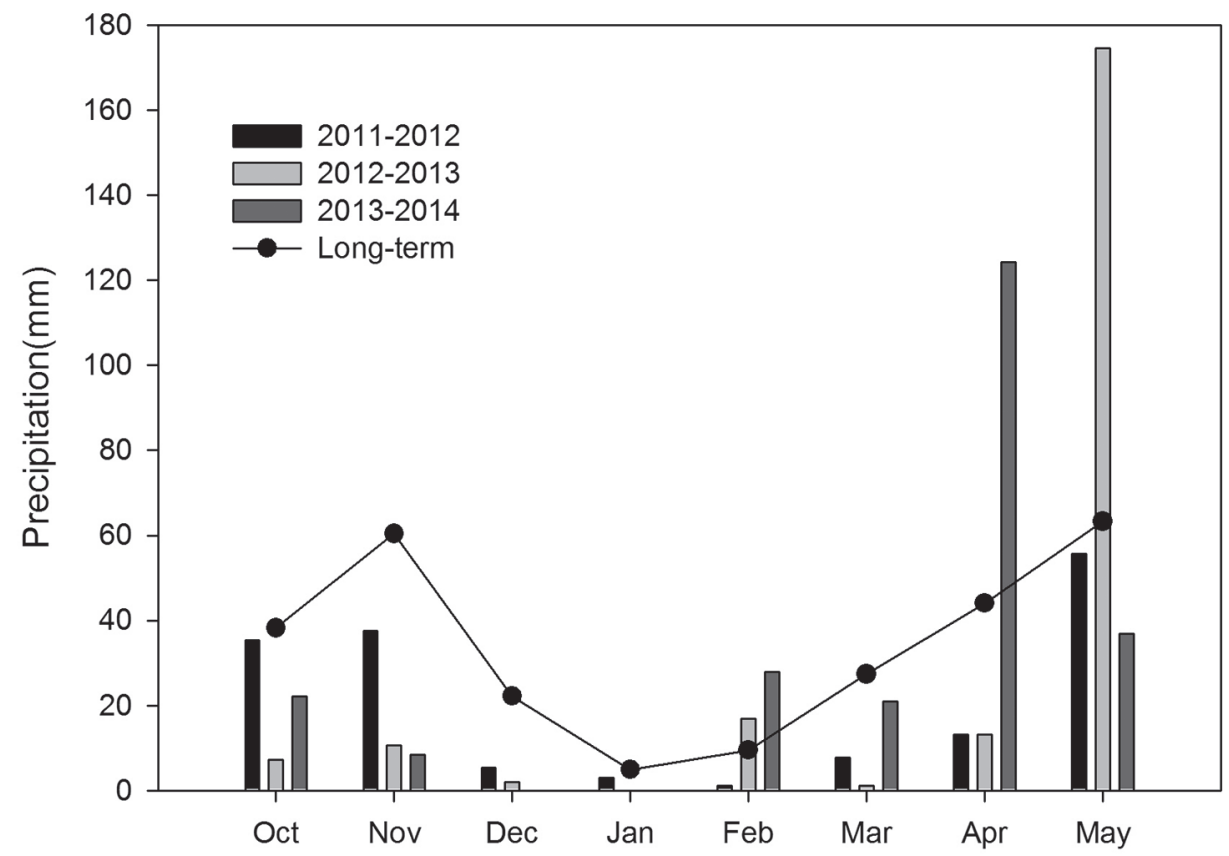

Figure 1. Precipitation during the experimental period (October-May of following year) compared with the long-term means (1956-2005) at the experimental site

\section{Plant sampling and determination}

After full heading, spikes flowering on the same date were labelled with red thread. Seven spikes in each plot were picked every 5 days from 5 days after anthesis until maturity. In 2013-2014, 10 spikes in each plot were picked at each sample time. From the basal 5 to 12 spikelets of every spike, the most basal grain and the most distal grain on each spikelet were detached and identified as superior and inferior grains, respectively (Jiang et al. 2003). Grains were dried until a constant weight was reached. The number of grains was then counted and their weights recorded.

At maturity in all three seasons, four central rows ( $1 \mathrm{~m}$ long) were harvested (only two rows in 2013-2014), counted, and weighed to determine the grain number per square meter, total above-ground biomass dry weight, grain yield and (harvest index) HI. Subsamples were used to record the grain number per spike and grain weight.

\section{Statistical analyses}

Differences among cultivars from different decades were evaluated with a coefficient of variance $(\mathrm{CV})$. 
The increase in grain weight during the grain filling period was fit to a logistic equation (Darroch and Baker, 1990) with Curve Expert software (Curve Expert 1.34, Hyams D G and Starkville M S, USA) as follows:

$$
\mathrm{W}=\mathrm{W}_{0} /\left(1+\mathrm{Ae}^{-\mathrm{B} t}\right) .
$$

In this equation, $\mathrm{W}_{0}$ represents the maximum grain weight and $\mathrm{t}$ represents the number of days after anthesis. The daily increase in grain weight (R), i.e., the grain filling rate, was calculated by the equation

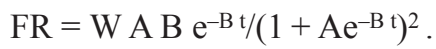

The average rate during the whole success of grain filling was calculated as

$$
\mathrm{FR}_{\mathrm{a}}=\mathrm{W}_{0} / \mathrm{T} \text {. }
$$

According to the two inflexion points of normal distribution, the whole process of grain development was divided into three periods, i.e., the lag, linear and mature periods (Liu et al. 1994), by the times $T_{1}$ and $T_{2}$, which were determined by the equations

and

$$
t_{1}=[\ln A-L N(2+\sqrt{ } 3)] / B
$$

$$
t_{2}=[\ln A+\operatorname{LN}(2+\sqrt{ } 3)] / B \text {. }
$$

The filling duration (FD) and average filling rate (FR) of kernels during these three periods were calculated as follows:

$$
\begin{gathered}
\mathrm{FD}_{1}=\mathrm{t} \quad \mathrm{FD}_{2}=\mathrm{t}_{2}-\mathrm{t}_{1} \quad \mathrm{FD}_{3}=\mathrm{T}-\mathrm{t}_{2} \\
\mathrm{FR}_{1}=\mathrm{W}_{1} / \mathrm{FD}_{1} \quad \mathrm{FR}_{2}=\left(\mathrm{W}_{2}-\mathrm{W}_{1}\right) / \mathrm{FD}_{2} \quad \mathrm{FR}_{3}=\left(\mathrm{W}-\mathrm{W}_{2}\right) / \mathrm{FD}_{3}
\end{gathered}
$$

In these expressions, $\mathrm{W}$ is the grain weight at complete maturity; $\mathrm{W}_{1}$ and $\mathrm{W}_{2}$ are the grain weights at times $t_{1}$ and $t_{2}$, respectively; and $T$ is the number of days from anthesis to maturity.

The exponential (the percentage grain yield gain per year) genetic gains of grain yield and related traits were modelled using the following equation:

$$
\ln (y i)=\mathrm{a}+\mathrm{b} x i+\mathrm{u} \text {. }
$$

In this equation, $\ln (y i)$ is the natural logarithm of $y i$, and $x i$ is the year in which cultivar $\mathrm{i}$ was released. The intercept was estimated by a, and the slope (b) measured exponential grain yield gains; the latter was converted to a percentage. The residual error was estimated by u (Ortiz-Monasterio et al. 1997). 


\section{Results}

\section{Relationship between $T G W$ and yield}

In our previous study, based on field crops research for three continuous seasons from 2010-2013 (Sun et al. 2014), a significant genetic gain of grain yield was closely and significantly related to the 1000 -grain weight increase $(r=0.764, \mathrm{P}<0.05)$. Table 2 shows that genetic gains in both irrigation treatments were greater than 1.2\% during 2013-2014, and the superiority of the 1000-grain weight of modern cultivars exhibited a significant annual gain of $0.47 \%$ in the irrigation treatment and $0.34 \%$ in the drought treatment, consistent with the results obtained in the previous three years.

\section{Grain filling characteristics and the relationship with $T G W$}

in 2011-2012 and 2012-2013

The increase in grain weight in wheat was close to sigmoidal, and the grain-filling rate displayed a normal distribution. Differences in filling characteristics among the cultivars were not consistent during 2011-2012 and 2012-2013 (Table 2 and Table S1*). Every cultivar introduced after the 1970 s exhibited higher $\mathrm{W}_{0}$ values than older cultivars. Although the parameters (FD, $\mathrm{FR}_{\mathrm{a}}$ ) varied differently among cultivars of different decades, no significant trend among decades was found. During 2011-2012, the CV of both FD and $\mathrm{FR}_{\mathrm{a}}$ decreased in the drought treatment but increased during 2012-2013. The $\mathrm{W}_{0}$ and FD of the 1990s were always the highest among all cultivars. During 2011-2012, the CV of FD was higher than that of $\mathrm{FR}_{\mathrm{a}}$, whereas the FR $\mathrm{a}$ was higher than of FD during 20122013.

The comparison among different decades in the three phases (lag, linear, and mature periods) showed that cultivar replacement did not cause significant effects on grain filling duration or rate. Drought raised the $\mathrm{CV}$ of filling rate $\left(\mathrm{FR}_{1}, \mathrm{FR}_{2}\right.$, and $\left.\mathrm{FR}_{3}\right)$ of all three phases in both seasons, but the CV of filling duration decreased during 2011-2012. In both irrigation treatments in 2011-2012, the CV of filling rate at linear and mature periods was always higher than that of filling duration; during 2012-2013, the CV of filling duration was higher than that of filling rate in all phases.

According to the correlation coefficient between the logistic parameters and the TGW of both 2011-2012 and 2012-2013 (Table S4), FD and the duration of each phase (FD ${ }_{1}$, $\mathrm{FD}_{2}$, and $\mathrm{FD}_{3}$ ) showed obvious influences on the TGW only in the irrigation treatment of 2012-2013. However, filling rate $\left(\mathrm{FR}_{\mathrm{a}}\right)$ and the rate of each phase positively and significantly influenced the TGW in both irrigation treatments of both seasons, especially in the irrigation treatment of 2012-2013 ( $\mathrm{P}<0.01)$. In different seasons, the filling rate of the different phases influenced the TGW differently, but it was clear that the filling rate of all phases was more influential on TGW under irrigation conditions than during drought.

\footnotetext{
*Further details about the Electronic Supplementary Material (ESM) can be found at the end of the article.
} 


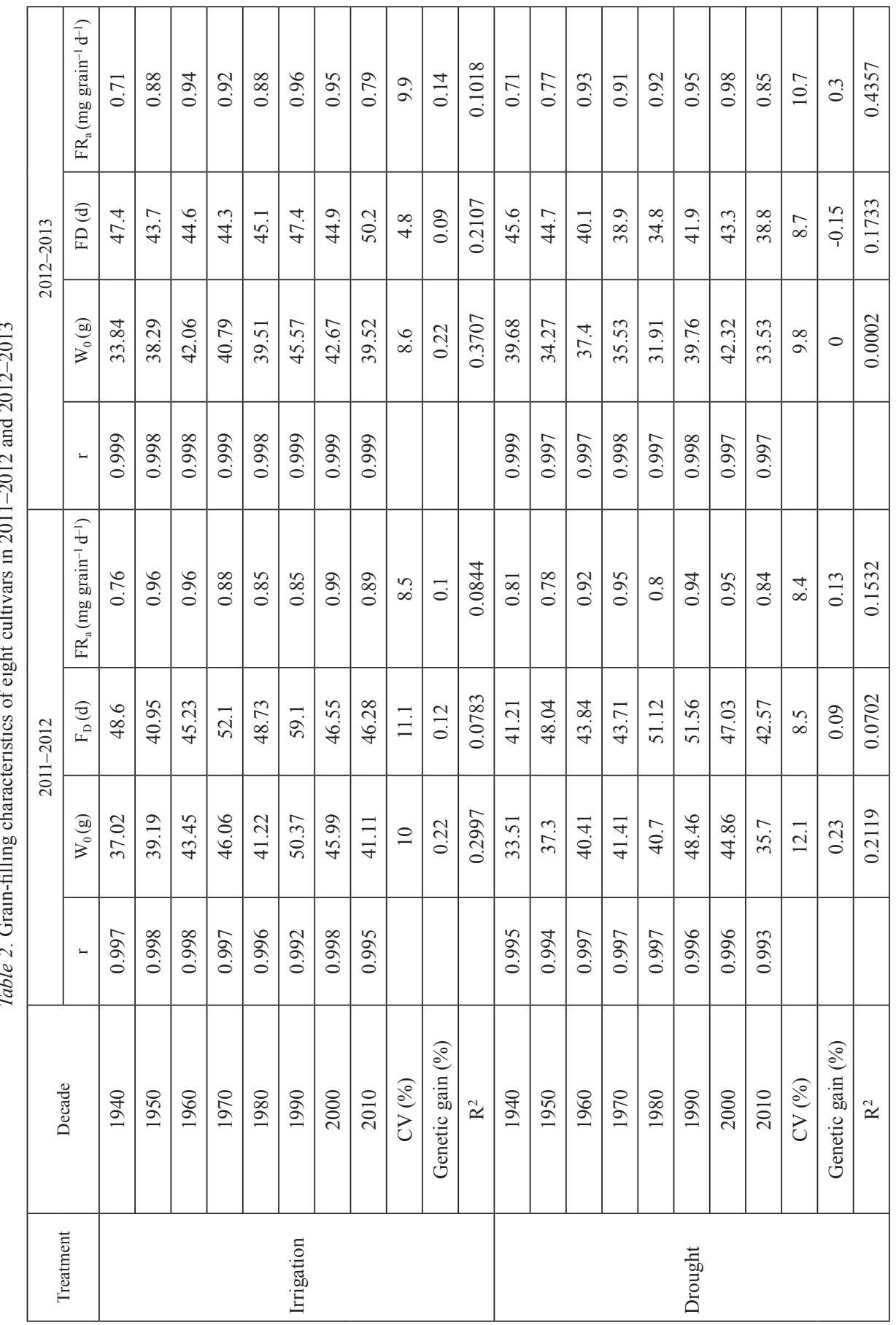




\section{Grain filling characteristics of superior/inferior grains and their relationship with TGW in 2013-2014}

In general, superior and inferior grains showed a similar trend with respect to grain filling (Tables S2, and S3), but the grain-filling trend in response to cultivar replacement was quite different from the trend characterizing grain filling in the whole spike. Modern cultivars possessed faster $\mathrm{FR}_{\mathrm{a}}$ than older ones in both irrigation treatments. For the superior grains, the annual genetic gains of FRa were higher in the drought treatment than in the irrigation treatment, whereas the inferior grains showed higher genetic gains in the irrigation treatments. The $\mathrm{CV}$ of $\mathrm{FR}_{\mathrm{a}}$ for both superior and inferior grains was higher than the FD in both irrigation and drought treatments. Most cultivars showed faster $\mathrm{FR}_{\mathrm{a}}$ in the irrigation treatment than in the drought treatment in both superior grains and inferior grains. With excessive precipitation at flowering (April) in 2013-2014 (Fig. 1), the flowering date and photosynthesis were adversely impacted. The FD values of both superior and inferior grains in most cultivars were longer under drought than under irrigation (Table $\mathrm{S} 2$ ). Significant genetic gains occurred for $\mathrm{FR}_{\mathrm{a}}$ in both superior and inferior grains, whereas the FD showed no obvious change with cultivar replacement. For superior grains, the CV of FD was decreased more under drought than under irrigation, but inferior grains exhibited opposite trend. In addition, the $\mathrm{FR}_{\mathrm{a}}$ showed a significant and positive correlation with the TGW.

The cultivars of the 2010 s possessed a shorter FD in the drought treatment, mainly due to the shorter $\mathrm{FD}_{1}$ (lag period, Table S3). The filling rates of all three phases made significant genetic improvement over the decades and positively influenced the TGW (Table S4). The filling rate of superior grains was more related with the TGW than the filling rate of inferior grains. Although the filling duration of each phase for inferior grains in the drought treatment presented markedly different CVs among cultivars, there was no obvious trend with cultivar replacement. According to the correlation coefficient between grain filling rate and duration of the eight cultivars (Table S4), only the $\mathrm{FR}_{2}$ and $\mathrm{FD}_{2}$ of irrigation in 2012-2013 showed a significant positive correlation $(\mathrm{r}=0.911, \mathrm{P}<0.01)$. In most stages and treatments, the filling rate decreased with an increase in duration.

\section{Discussion}

Many studies confirm that yield is far more closely associated with grain number than with grain weight (Fischer 2007; Miralles and Slafer 2007). However, grain weight showed a more positive influence on yield than grain number in the present study (data shown in Sun et al. 2014), which is consistent with the results presented by Aisawi et al. (2010). Grain development is determined by the availability of assimilates, the growth potential of the grain, and the resistance within the phloem to the movement of assimilates to the grain (Bremner and Rawson 1978).

Pronounced differences among cultivars in growth rate per grain have been found. For example, in the experiments of Asana and Williams (1965), faster rates were associated with larger but fewer grains per ear. Differences among cultivars in the duration of grain 
filling were found by Stoy (1965) and Rawson and Evans (1971). Marcellos and Single (1972) found no differences in duration among the four cultivars they examined. In the present study, the cultivars differed significantly in the rate and duration of grain filling in both 2011-2012 and 2012-2013 (Tables 2 and S1), but there was no evident trend with cultivar replacement. Cultivars of the 1990s and 2000s presented the highest FR (Table 2 ), especially in the lag and linear periods (Table S1), but the change was not linearly consistent among the cultivars introduced. The results were slightly different from those of previous studies, indicating that modern breeding work in this area might have been conducted with varying objectives.

According to a previous study on the Loess Plateau, modern wheat cultivars possess faster filling rates, which was the most important factor affecting increased grain weight (Zhang et al. 2008). This finding was consistent with the results of the present study. During the development of wheat grains, $\mathrm{FR}_{\mathrm{a}}, \mathrm{FR}_{1}, \mathrm{FR}_{2}$ and $\mathrm{FR}_{3}$ caused great effects on the dry matter accumulation of grain weight and filling duration was less influential on final grain weight (Table S4). Even if grains in different positions were involved, the filling rates of all three periods had a greater influence on final grain weight than did the filling duration. Similar conclusions were reported by Chanda et al. (2002). Genotypes with high $\mathrm{FR}_{1}, \mathrm{FR}_{2}$ and $\mathrm{FR}_{3}$; long $\mathrm{D}_{1}$ and $\mathrm{D}_{2}$; and short $\mathrm{D}_{3}$ should steadily produce heavy grains (Liu et al. 1994). In Shaanxi Province, China, a longer duration was only an important factor when the precipitation during grain filling was excessive and when photosynthesis was seriously restricted in light-limited environments (Fig. 1). Therefore, focusing on increasing grain weight to increase yield would be more effecting than increasing the duration of the grain-filling stage.

Gebeyehou et al. (1982) concluded that simultaneous selection for increases in rates of grain filling and grain weight should occur without increasing the duration of grain filling because there was no detectable genetic relationship between the rate and duration of grain filling. Similar results were obtained by Nass and Reiser (1975). Different results were obtained in the present study, and with a few exceptions, the $\mathrm{FR}_{\mathrm{a}}$ and FR of all three periods were always negatively correlated with the duration of grain filling (Table S4). Further increases in the filling rate might be accompanied by decreases in the filling duration, which is a disadvantage for further breeding work in this area. The focus of future breeding programs must be on how to obtain a higher grain yield with a balance of these two parameters.

Lower $\mathrm{FR}_{2}$ and $\mathrm{FR}_{3}$ and shorter $\mathrm{FD}_{1}$ and $\mathrm{FD}_{2}$ were the causes for the decreased $\mathrm{FR}_{\mathrm{a}}$ and FD of most cultivars under drought conditions during both 2011-2012 and 2012-2013 (Tables 2 and 3). Under the drought treatment, sufficient water was provided after the recovering stage, which might have led to the water deficit delay and resulted in a compensation effect (Bielorai et al. 1975); winter wheat might present similar or even faster FR in response to light drought during the lag period.

Recent studies have indicated that earlier-flowering superior spikelets exhibit dominance over later-flowering inferior spikelets. High ethylene production and low ABA content in inferior spikelets result in slow endosperm cell division and poor grain filling, which lead to low grain weight (Yang et al. 2006). The FD between superior and inferior 
grains showed no significant differences (Table S2), although inferior grains were regarded as late flowering (Yang et al. 2006). The most important reason for the lower weight of inferior grains than of superior grains (Fig. 2) was the lower FR (Table S2), especially the $\mathrm{FR}_{2}$ (Table S3), which is supported by the conclusion that FR (especially $\mathrm{FR}_{2}$ ) is the main factor determining grain weight (Gebeyehou et al. 1982).

In contrast to the unapparent trends in the grain-filling characteristics of whole spikes over decades (Tables 2 and $\mathrm{S} 1$ ), the filling rate, especially the $\mathrm{FR}_{\mathrm{a}}$ and $\mathrm{FR}_{1}$ of superior and inferior grains, showed significant and positive correlations with time (Tables S2 and S3). In this study, both superior and inferior grains were collected from the middle spikelets of the spikes (Jiang et al. 2003). It might be concluded that (at least in this area) modern wheat cultivars possess faster filling rates in the middle of the spikes than older cultivars; however with the combined rates of top and bottom grains, the filling rate of the whole spike did not increase. Additional studies on the grain filling process of the grains at the top and bottom of spikes are needed, as the grain-filling characteristics of a spike are determined by all grains at different positions in the spike.

\section{Conclusions}

Taken together, our results demonstrate that the filling rate, especially the filling rate of the lag and linear periods, was the main source for grain weight in cultivars grown in Shaanxi Province, China. Maintaining faster filling rates with shorter filling durations in drought is a practical way to achieve higher yields while maintaining drought resistance. Although the filling rates of the superior and inferior grains in the middle of the spikes have been improved with cultivar replacement, determining how to increase the movement of carbohydrates to the grains of the whole spike requires further research.

\section{Acknowledgements}

This work was supported by the National Science-technology Support Plan Projects (2015BAD22B01), and National Science Foundation (31500320).

\section{References}

Aggarwal, P.K., Sinha, S.K. 1984. Effect of water stress on grain growth and assimilate partitioning in two cultivars of wheat contrasting in their yield in a drought environment. Ann. Bot-London. 53:329-340.

Aisawi, K., Foukes, J., Reynolds, M., Mayes, S. 2010. The physiological basis of genetic progress in yield potential of CIMMYT wheat varieties from 1966 to 2009. In: Abstracts 8th International Wheat Conference, St Petersburg, Russia 1-4 June 2010, p. 349.

Asana, R.D., Williams, R.F. 1965. The effect of temperature stress on grain development in wheat. Aust. J. Aag. Res. 16:1-13.

Bielorai, H., Hopmans, P.A.M. 1975. Recovery of leaf water potential, transpiration, and photosynthesis of cotton during irrigation cycles. Agron. J. 67:629-632.

Bremner, P.M., Rawson, H.M. 1978. The weights of individual grains of the wheat ear in relation to their growth potential, the supply of assimilates and interaction between grains. Aust. J. Plant. Physiol. 5:61-72. 
Chanda, S.V., Singh, Y.D. 2002. Source-sink relationships and grain weight at different positions within wheat spike. Plant Breeding Seed Sci. 46:67-73.

Darroch, B.A., Baker, R.J. 1990. Grain Filling in Three Spring Wheat Genotypes: Statistical Analysis. Crop Sci. 30:525-529.

Finlay, G.J., Bullock, P.R., Sapirstein, H.D., Naeem, H.A., Hussain, A., Angadi, S.V., DePauw, R.M. 2007. Genotypic and environmental variation in grain, flour, dough and bread-making characteristics of western Canadian spring wheat. Can. J. Plant Si. 87:679-690.

Fischer, R.A. 2007. Understanding the physiological basis of yield potential in wheat. J. Agr. Sci. 145:99-113.

Fischer, R.A., Maurer, R. 1978. Drought resistance in spring wheat cultivars. I. Grain yield response. Aust. J. Agr. Res. 29:897-912.

Gebeyehou, G., Knott, D.R., Baker, R.J. 1982. Rate and Duration of Grain Filling in Durum Wheat Cultivars. Crop Sci. 22:337-340.

Ishimaru, T., Matsuda, T., Ohsugi, R., Yamagishi, T. 2003. Morphological development of rice caryopses located at the different positions in a panicle from early to middle stage of grain filling. Funct. Plant Biol. 30:1139-1149.

Jiang, D., Cao, W.X., Dai, T.B., Jing, Q. 2003. Activities of key enzymes for starch synthesis in relation to growth of superior and inferior grains on winter wheat (Triticum aestivum L.) spike. Plant Growth Regul. 41:247-257.

Li, F.R., Zhao, S.L., Geballe, G.T. 2000. Water use patterns and agronomic performance for some cropping systems with and without fallow crops in a semi-arid environment of northwest China. Agr. Ecosyst. Environ. 79:129-142.

Liu, Z.Q., Li, Y.C. 1994. Heterosis of grain weight in wheat hybrids with Triticum timopheevi cytoplasm. Euphytica 75:189-193.

Marcellos, H., Single, W.V. 1972. The influence of cultivar, temperature, and photoperiod on post-flowering development of wheat. Aust. J. Agr. Res. 23:533-540.

Miralles, D.J., Slafer, G.A. 2007. Sink limitations to yield in wheat: how could it be reduced? J. Agr. Sci. 145:139-149.

Mohapatra, P.K., Sahu, S.K. 1991. Heterogeneity of primary branch development and spikelet survival in rice in relation to assimilates of primary branches. J. Exp. Bot. 42:871-879.

Murty, P.S.S., Murty, K.S. 1982. Spikelet sterility in relation to nitrogen and carbohydrate contents in rice. Indian J. Plant Physiol. 25:40-48.

Nass, H.G., Reiser, B. 1975. Grain filling period and grain yield relationships in spring wheat. Can. J. Plant Sci. 55:673-678.

Ortiz-Monasterio, R., Sayre, K.D., Rajaram, S., McMahon, M. 1997. Genetic progress in wheat yield and nitrogen use efficiency under four nitrogen rates. Crop Sci. 37:898-904.

Rawson, H.M., Evans, L.T. 1971. The contribution of stem reserves to grain development in a range of wheat cultivars of different height. Aust. J. Agr. Res. 22:851-863.

Sofield, I., Evans, L.T., Cook, M.G., Wardlaw, I.F. 1977. Factors influencing the rate and duration of grain filling in wheat. Aust. J. Plant Physiol. 4:785-797.

Stoy, V. 1965. Photosynthesis, respiration and carbohydrate accumulation in spring wheat in relation to yield. Plant Physiol. Suppl. 4:1-125.

Sun, Y.Y., Wang, X.L., Wang, N., Chen, Y.L., Zhang, S.Q. 2014. Changes in the yield and associated photosynthetic traits of dry-land winter wheat (Triticum aestivum L.) from the 1940s to the 2010s in Shaanxi Province of China. Field Crops Res. 167:1-10.

Yang, J.C., Peng, S.B., Visperas, R.M., Sanico, A.L., Zhu, Q.S., Gu, S.L. 2000. Grain filling pattern and cytokinin content in the grains and roots of rice plants. Plant Growth Regul. 30:261-270.

Yang, J.C., Zhang, J.H., Liu, K., Wan, Z.Q., Liu, L.J. 2006. Abscisic acid and ethylene interact in wheat grains in response to soil drying during grain filling. New Phytol. 171:293-303.

Yang, W.B., Yin, Y.P., Li, Y., Cai, T., Ni, Y.L., Peng, D.L., Wang, Z.L. 2014. Interactions between polyamines and ethylene during grain filling in wheat grown under water deficit conditions. Plant Growth Regul. 72:189-201. 
Zhang, C.H., Jiang, D., Liu, F.L., Cai, J., Dai, T.B., Cao, W.X. 2010. Starch granules size distribution in superior and inferior grains of wheat is related to enzyme activities and their gene expressions during grain filling. J. Cereal Sci. 51:226-233.

Zhang, Y., Hao, M.D., Pang, Y.H. 2008. Study on the Grain filling Characteristic of the Succession of Wheat Cultivars in the Gully Areas of the Loess Plateau. J. Triticeae Crops 28:1058-1062 (In Chinese with English abstract).

\section{Electronic Supplementary Material (ESM)}

Electronic Supplementary Material (ESM) associated with this article can be found at the website of CRC at https://akademiai.com/loi/0806/

Electronic Supplementary Table S1. Grain-filling characteristics of different periods of eight cultivars in 2011-2012

Electronic Supplementary Table S2. Grain-filling characteristics of superior and inferior grains of eight cultivars in 2013-2014

Electronic Supplementary Table S3. Grain-filling characteristics of different periods of the superior grains of eight cultivars in 2013-2014

Electronic Supplementary Table S4. Correlation coefficient between logistic parameters and 1000-grain weights of eight cultivars 